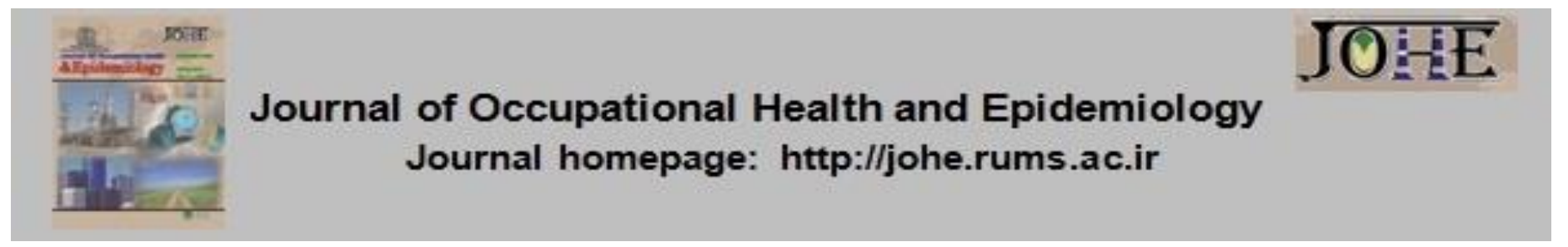

\title{
An Epidemiological Survey of Mortality among Patients Admitted in Ali Ibn Abitaleb Hospital in Rafsanjan, Southeast Iran, 2019
}

\author{
Mohammad Ali Zakeri ${ }^{1}$, Maryam Zakeri ${ }^{2}$, Sayed Mortaza Hossini Rafsanjanipoor ${ }^{3^{*}}$ \\ 1. MSc in Nursing, Social Determinants of Health Research Centre, Rafsanjan University, Rafsanjan, Iran; Non-Communicable \\ Diseases Research Center, Rafsanjan University of Medical Sciences, Rafsanjan, Iran. \\ 2. MSc in Physiology, Physiology-Pharmacology Research Center, Research Institude of Basic Medical Sciences, Rafsanjan \\ University of Medical Sciences, Rafsanjan, Iran. \\ 3. MSc in Epidemiology, Social Determinants of Health Research Centre, Rafsanjan University, Rafsanjan, Iran.
}

$$
\begin{aligned}
& \text { Citation: Zakeri MA, Zakeri M, Hossini Rafsanjanipoor SM. An Epidemiological Survey of } \\
& \text { Mortality among Patients Admitted in Ali Ibn Abitaleb Hospital in Rafsanjan, Southeast Iran, } \\
& \text { 2019. JOHE 2020; 9(4):219-24. }
\end{aligned}
$$

\section{Article Info}

* Corresponding author:

Sayed Mortaza Hossini

Rafsanjanipoor,

E-mail:

mhosseini622@gmail.com

\section{Article history \\ Received: Oct 2020 \\ Accepted: Feb 2021}

10.29252/johe.9.4.219

Print ISSN: 2251-8096 Online ISSN: 2252-0902

Peer review under responsibility of Journal of Occupational Health and Epidemiology

\section{Abstract}

Background: Investigating information on the causes of death of patients is an undeniable necessity for health policy and disease control at the level of human societies. This study aimed to perform an epidemiological study on patient mortality in Ali Ibn Abitaleb Hospital in Rafsanjan, Southeastern Iran, 2019.

Materials and Methods: In this descriptive study, 260 patients who died during March to September, 2019 were reviewed. Data were collected from patients' records using a predesigned checklist. Data were analyzed using t-test and one-way analysis of variance.

Results: The highest proportion of death was due to internal diseases (38.8\%). The mean duration of hospitalization in the emergency ward was 7.14 hours and in other wards was 180.36 hours. The mean time from admission to initial visit was $57.91 \pm 29.16$ minutes, to death was 185.20 hours, and to Cardiopulmonary Resuscitation (CPR) time was $29.82 \pm 19.29$ minutes. The cause of death in various groups of patients was significantly different based on their age and the duration of being admitted in hospital $(P$ $<0.001$ ).

Conclusions: Our findings suggested the importance of controlling and preventing internal diseases in the population from that patients referred to this hospital. More investigation on the duration of hospitalization in the ward (by assessing the association between complications due to prolonged hospital stay and mortality) can play an effective role in preventing long-term hospitalization deaths.

Keywords: Patient, Mortality, Hospital, Epidemiological Study.

\section{Introduction}

Epidemiological study of the causes of mortality is an undeniable necessity for health policy and disease control and even accountability at the community level. Identifying the pattern and causes of death and dealing with its etiological factors is one of the most appropriate strategies to increase life expectancy. Obtaining this information is one of the most basic principles of planning, management, evaluation, and responsibility in the health sector in countries [1]. Many studies have been focused on reducing preventable deaths in hospitals and improving treatments and services [2]. Mortality based on different age groups and gender represents the status of health care services and the level of the economic benefit of different groups in society [3], which can be due to the economic conditions prevailing in society, reflecting economic developments at some point in time and indicating the rate of society's growth. Also, its comparison in different sectors, including urban and rural areas, and groups of men and 
women, can determine the fair or unfair distribution of resources, income, and facilities [4]. Hospital mortality accounts for a large proportion of community deaths. Its rate is closely related to hospital medical facilities and equipment, number and quality of medical and nursing care, type of hospital, quality and number of different hospital wards, characteristics of hospitalized patients, and also types and severity of diseases. The need for reliable information on the causes of death is an undeniable necessity for health policy and disease control at the level of human societies. Since death occurs only once in a person's life, it is a serious and objective event, and it is more practical and easier to record deaths than illnesses [5]. Numerous studies have been conducted in different countries on the trend of death changes; mortality statistics of most countries are published by the World Health Organization [6]. Ellen Bach et al. state that studying the cause of death to recognize and prevent them by eliminating the risk factors can be useful to increase life expectancy [7]. Epidemiological studies usually begin with mortality data. Studies show changes in the causes of death from infectious to chronic diseases due to advances in technology in the diagnosis and treatment. Therefore, it is important to identify past and present changes, mortality trends, and factors that may increase life expectancy in the future [8]. In Iran, the Ministry of Health, Treatment, and Medical Education, with the participation of the Civil Registration Organization, has implemented a program to register deaths based on their cause and characteristics, taking an important step in determining the mortality pattern in the country and monitoring the process. The results benefit the development, design, and implementation of intervention and public health programs. Identifying the mortality pattern and monitoring its trend help determine health priorities to allocate resources properly to the health sector, beside eliminating the main causes of premature death [9].

Thus far, no study has been conducted to epidemiologically collect and analyze data related to the mortality of patients referred to Hazrat Ali lbn Abitaleb Hospital in Rafsanjan. Therefore, to better diagnosis causes of death, present study aims to epidemiologically investigate the mortality rate of patients admitted to Ali Ibn Abitaleb Hospital in Rafsanjan in 2019, the largest and most important hospital in the city with the most admissions, including referral and non-referral. The results of this study can be effective in the future planning of university and college officials to reduce hospital mortality.

\section{Materials and Methods}

This descriptive study was performed over six months from 2019 March to 2019 September on all patients referred to Hazrat Ali Ibn Abitaleb Hospital in Rafsanjan. It is necessary to mention that this hospital is the only general and referral hospital in this city that most critically ill patients are referred to this center due to their centralized treatment and general hospitality. Therefore, the number of deaths in this hospital confirms most deaths occur in general and referral medical centers.

The statistical population included all patients who died in the hospital, and the study sample consisted of all 260 records related to patients who died in the wards, except for the emergency department, from 2019 March to 2019 September. Inclusion criteria included cases transferred to the ward after admission to the emergency department and then died there. Exclusion criteria included those who died on arrival at the hospital or lacked any vital signs, as well as those who died in the emergency department.

The data used included demographic characteristics of the deceased (age, sex, marital status, place of residence, and nationality), the hospital referral type (outpatient, EMS, office visits), triage level, intubation status during admission, hospitalization service, matching the initial diagnosis with the final diagnosis, an average time between admission and initial visit, duration of hospitalization, time transfer time to ward, length of stay in the ward, and time between admission to the emergency room and death. The causes of mortality were also assessed using the ICD-10 (International Classification of Disease) criterion.

Based on ICD-10, they were divided into the following eight main groups: 1- Cardiovascular diseases 2- Diseases caused by external causes (accidents and poisonings) 3- Internal diseases 4Infectious diseases 5- Surgical diseases 6Neurological diseases 7- Malignancies 8- Final diagnosis unknown. First, after coordination with the head of the health information technology unit and the expert of the hospital statistics unit, a list of all patients who died during this period was prepared; then, the required information was extracted from the patients' records using a predesigned statistical form. In order to analyze data, SPSS version 22 statistical software was used. Descriptive statistics, such as mean, standard deviation, ratio, and frequency, were used to describe the data; further, t-test and analysis of variance were used to analyze the data and determine the relationship between variables. Using the Kolmogorov-Smirnov test, the 
hypothesis of normality of quantitative variables was examined, and it was found that all variables had a normal distribution. The significance level in all tests was less than 0.05 .

Ethics Committee of Rafsanjan University of Medical Sciences approved the study protocol (IR.RUMS.REC.1398.165).

\section{Results}

Out of 260 patients who died in different wards of Hazrat Ali Ibn Abitaleb (AS) Hospital in Rafsanjan from 2019 March to 2019 September, the two age groups of 85-75 years and> 85 years with 132 cases $(50.8 \%)$ had the highest and the age group of $5-15$ years with 3 people (2/2). 1\%) had the lowest mortality rate (Table 1 ).

Table 1. Demographic variables of death cases $(N=260)$

\begin{tabular}{|c|c|c|c|c|c|}
\hline \multicolumn{2}{|c|}{ Cases characteristics } & \multirow{2}{*}{$\begin{array}{c}\begin{array}{c}\text { Frequency } \\
\text { (Percent) }\end{array} \\
142(54.60)\end{array}$} & \multicolumn{2}{|c|}{ Cases characteristics } & \multirow{2}{*}{$\begin{array}{c}\begin{array}{c}\text { Frequency } \\
\text { (Percent) }\end{array} \\
30(11.60)\end{array}$} \\
\hline Gondar & Male & & \multirow{7}{*}{$\begin{array}{c}\text { Cause of } \\
\text { death }\end{array}$} & Cardiovascular disease & \\
\hline Geinuel & Female & $118(45.40)$ & & Internal disease & $101(39.10)$ \\
\hline \multirow{2}{*}{ Marriage } & Single & $43(16.50)$ & & Infectious disease & $36(14.00)$ \\
\hline & Married & $217(83.50)$ & & Surgical disease & $10(3.90)$ \\
\hline \multirow{2}{*}{ Residence } & Urban & $165(63.50)$ & & Neurological disease & $37(14.30)$ \\
\hline & Rural & $94(36.50)$ & & Malignancies & $24(9.30)$ \\
\hline \multirow{7}{*}{$\begin{array}{l}\text { Inpatient } \\
\text { service }\end{array}$} & Medical & $144(55.40)$ & & External factors & $20(7.80)$ \\
\hline & Surgery & $21(8.10)$ & \multirow{11}{*}{$\begin{array}{l}\text { Ward of } \\
\text { death }\end{array}$} & $\mathrm{ICU}$ & $203(79.61)$ \\
\hline & Heart & $25(9.60)$ & & $\mathrm{CCU}$ & $17(6.67)$ \\
\hline & Pediatric & $19(7.30)$ & & NICU & $20(7.84)$ \\
\hline & Infectious & $9(3.50)$ & & PICU & $1(0.39)$ \\
\hline & Neurology & $22(8.50)$ & & Pediatric & $1(0.39)$ \\
\hline & Neurosurgery & $20(7.70)$ & & Neurology & $3(1.18)$ \\
\hline \multirow{4}{*}{$\begin{array}{l}\text { Referral } \\
\text { method }\end{array}$} & Personal & $65(26.00)$ & & Oncology & $1(0.39)$ \\
\hline & EMS & $153(61.00)$ & & Endocrine & $1(0.39)$ \\
\hline & $\begin{array}{l}\text { Hospitalization } \\
\text { order }\end{array}$ & $14(6.00)$ & & Medical & $5(1.96)$ \\
\hline & Other centers & $19(7.00)$ & & Dialysis & $2(0.78)$ \\
\hline \multirow{2}{*}{ Triage level } & 1 & $151(61.60)$ & & Surgery room & $1(0.39)$ \\
\hline & 2 & $94(38.40)$ & Age (year) & \multicolumn{2}{|c|}{$M \pm S D(70 / 06 \pm 22.75)$} \\
\hline
\end{tabular}

*Because some variables are not recorded for some people (Missing Data), the sum of the levels in the different variables is not the same.

Of the total cases, in 139 cases (53.5\%), compliance was observed, and in other cases, a discrepancy was observed between the initial and final diagnosis. The average length of hospital stay of the deceased in the emergency room was 7.14 hours; further, hospital stay in the ward, admission to the initial visit, duration of admission to death, and duration of resuscitation were 180.36 hours, 29.16 minutes, 185.20 hours, and 29.82 minutes respectively (Table 2 ).

Table 2. Time variables of death by gender, Ali Ibn Abitaleb Hospital in Rafsanjan, Southeastern Iran, $2019(\mathrm{~N}=260)$

\begin{tabular}{|c|c|c|c|c|}
\hline Variable & Gender & Frequency * (Percent) & $\begin{array}{l}\text { Mean } \\
M \pm S D\end{array}$ & P-value ** \\
\hline \multirow{2}{*}{ Age } & Female & $111(46)$ & $74.17 \pm 19.85$ & \multirow{2}{*}{$.008^{\star *}$} \\
\hline & Male & $131(54)$ & $66.58 \pm 24.47$ & \\
\hline \multirow{2}{*}{$\begin{array}{c}\text { Time to stay in the emergency } \\
\text { ward (hours) }\end{array}$} & Female & $110(45)$ & $7.55 \pm 17.00$ & \multirow{2}{*}{.760} \\
\hline & Male & $132(55)$ & $6.80 \pm 20.26$ & \\
\hline \multirow{2}{*}{$\begin{array}{l}\text { Time to stay in the others wards } \\
\text { (hours) }\end{array}$} & Female & $108(46)$ & $178.30 \pm 228.27$ & \multirow{2}{*}{.896} \\
\hline & Male & $129(54)$ & $182.08 \pm 214.68$ & \\
\hline \multirow{2}{*}{$\begin{array}{c}\text { Time of admission until initial } \\
\text { visit (minutes) }\end{array}$} & Female & $113(45)$ & $27.36 \pm 62.79$ & \multirow[b]{2}{*}{.655} \\
\hline & Male & $137(55)$ & $30.65 \pm 53.74$ & \\
\hline \multirow{2}{*}{$\begin{array}{l}\text { Time of admission until death } \\
\text { (hours) }\end{array}$} & Female & $114(46)$ & $184.86 \pm 223.14$ & \multirow{2}{*}{.982} \\
\hline & Male & $135(54)$ & $185.48 \pm 213.56$ & \\
\hline \multirow{2}{*}{ Time of CPR } & Female & $117(45)$ & $30.39 \pm 27.26$ & \multirow{2}{*}{.969} \\
\hline & Male & $142(55)$ & $29.35 \pm 8.29$ & \\
\hline
\end{tabular}

*Because some variables are not recorded for some people (missing data), the sum of the levels in the different variables is not the same.

**Independent T-Test; at a 5\% Level

According to Table 2, using the independent t-test, the mean of age and time in the studied patients were compared in the male and female groups. Only in terms of age, a significant difference was 
observed between men and women. The mean age of men and women who died were $66.58 \pm 24.47$ and $74.17 \pm 19.85$ years, respectively, which was statistically significant $(P=0.008)$. Using one-way analysis of variance, the mean age, duration of hospitalization, and the duration of studies related to deceased patients were compared according to the cause of death. Only in terms of age, hospital stay length, and admission to death, a significant difference was observed between the deceased in terms of the cause of death $(P<0.001)$. The longest hospital stay and admission to death were related to neurological patients (Table 3 ).

Table 3. Time variables of death by the cause of death, Ali Ibn Abitaleb Hospital in Rafsanjan, Southeastern Iran, 2019 $(\mathrm{N}=260)$

\begin{tabular}{|c|c|c|c|c|}
\hline Variable & Cause of death & Frequency*(percent) & Mean \pm SD & P-value ${ }^{\star \star}$ \\
\hline \multirow{7}{*}{ Age } & Cardiovascular & $29(12.08)$ & $67.48 \pm 25.66$ & \multirow{7}{*}{.$<0.001^{\star *}$} \\
\hline & External & $20(8.32)$ & $41.60 \pm 21.98$ & \\
\hline & Internal & $84(35)$ & $73.68 \pm 23.06$ & \\
\hline & Infectious & $36(15)$ & $77.53 \pm 15.71$ & \\
\hline & Surgical & $10(4.16)$ & $72.00 \pm 17.58$ & \\
\hline & Neorologiacal & $37(15.42)$ & $73.65 \pm 19.90$ & \\
\hline & Malignancies & $24(10)$ & $66.71 \pm 17.03$ & \\
\hline \multirow{7}{*}{$\begin{array}{l}\text { Time to stay in the } \\
\text { emergency ward (hours) }\end{array}$} & Cardiovascular & $30(12.5)$ & $2.53 \pm 1.67$ & \multirow{7}{*}{.743} \\
\hline & External & $19(7.9)$ & $4.26 \pm 2.24$ & \\
\hline & Internal & 87 (36.3) & $8.27 \pm 25.07$ & \\
\hline & Infectious & $34(14.2)$ & $10.17 \pm 20.33$ & \\
\hline & Surgical & $10(4.2)$ & $6.65 \pm 10.17$ & \\
\hline & Neorologiacal & $36(15)$ & $7.71 \pm 20.07$ & \\
\hline & Malignancies & $24(10)$ & $6.01 \pm 7.06$ & \\
\hline \multirow{7}{*}{$\begin{array}{l}\text { Time to stay in the others } \\
\text { wards (hours) }\end{array}$} & Cardiovascular & $30(12.8)$ & $86.23 \pm 193.69$ & \multirow{7}{*}{$.046^{\star *}$} \\
\hline & External & $19(8.1)$ & $129.16 \pm 148.25$ & \\
\hline & Internal & $85(36.2)$ & $180.48 \pm 205.13$ & \\
\hline & Infectious & $32(13.6)$ & $203.86 \pm 289.45$ & \\
\hline & Surgical & $10(4.3)$ & $127.55 \pm 112.55$ & \\
\hline & Neorologiacal & $35(14.9)$ & $263.56 \pm 240.06$ & \\
\hline & Malignancies & $24(10.2)$ & $198.55 \pm 207.98$ & \\
\hline \multirow{7}{*}{$\begin{array}{l}\text { Time of admission until } \\
\text { initial visit (minutes) }\end{array}$} & Cardiovascular & $30(12.1)$ & $13.13 \pm 19.92$ & \multirow{7}{*}{.438} \\
\hline & External & $20(8.1)$ & $40.75 \pm 78.99$ & \\
\hline & Internal & $93(37.5)$ & $25.84 \pm 48.44$ & \\
\hline & Infectious & $35(14.1)$ & $34.51 \pm 86.44$ & \\
\hline & Surgical & $10(4)$ & $25.60 \pm 31.50$ & \\
\hline & Neorologiacal & $36(14.5)$ & $28.33 \pm 60.11$ & \\
\hline & Malignancies & $24(9.7)$ & $46.58 \pm 57.90$ & \\
\hline \multirow{7}{*}{$\begin{array}{c}\text { Time of admission until } \\
\text { death (hours) }\end{array}$} & Cardiovascular & $30(12.1)$ & $88.76 \pm 194.03$ & \multirow{7}{*}{$.030^{\star *}$} \\
\hline & External & $19(7.7)$ & $133.42 \pm 149.81$ & \\
\hline & Internal & $96(38.9)$ & $183.30 \pm 199.75$ & \\
\hline & Infectious & $33(13.4)$ & $211.59 \pm 285.16$ & \\
\hline & Surgical & $10(4)$ & $134.19 \pm 120.83$ & \\
\hline & Neorologiacal & $35(14.2)$ & $271.26 \pm 236.27$ & \\
\hline & Malignancies & $24(9.7)$ & $204.57 \pm 207.99$ & \\
\hline \multirow{7}{*}{ Time of CPR } & Cardiovascular & $29(11.3)$ & $27.93 \pm 8.82$ & \multirow{7}{*}{.637} \\
\hline & External & $20(7.8)$ & $29.25 \pm 8.63$ & \\
\hline & Internal & $101(39.3)$ & $32.92 \pm 29.34$ & \\
\hline & Infectious & $36(14)$ & $28.19 \pm 8.29$ & \\
\hline & Surgical & $10(3.9)$ & $27.50 \pm 4.25$ & \\
\hline & Neorologiacal & $37(14.4)$ & $27.43 \pm 6.08$ & \\
\hline & Malignancies & $24(9.3)$ & $27.08 \pm 5.50$ & \\
\hline
\end{tabular}

*Because some variables are not recorded for some people ( Missing Data), the sum of the levels in the different variables is not the same.

** One-Way ANOVA; at a 5\% Level

\section{Discussion}

According to the research findings, out of a total of 260 patients who died in different wards of this hospital, 142 (54.6\%) were men and 118 (45.4\%) were women; this was in line with the Sepandi et al., with a death rate of $423(60 \%)$ men and 266 (37.73\%) women out of a total of 705 cases [10] and Garkaz et al., with a death rate of $153(54.1 \%)$ male and 130 (45.9\%) female out of 283 [11]. The higher rate of death in men than women can be attributed to the higher rate of injuries and deaths due to external causes, such as accidents, as well as early doctor visits by women and their greater sensitivity to their health. This result is also expected due to a higher mortality rate from 
cardiovascular diseases and cerebrovascular accidents in men than women. In the present study, the mean age of individuals was $70.06 \pm 22.75$ years, and the highest frequency of death was between 85-75 years and over 85 years $(50.8 \%)$. The highest frequency of death was observed in the age group of 70 to 79 years, consistent with [1]. It can be said that old age makes people vulnerable to diseases. Also, according to this study results, $66.6 \%$ of the causes of diseases were related to internal, infectious, and neurological diseases, and $78.1 \%$ of the deaths were in the intensive care unit. This is since people admitted to the intensive care unit usually have other underlying problems, such as high blood pressure, cardiovascular disease, respiratory problems, and diabetes, increasing mortality. In this study, out of a total of 260 deaths, 217 (83.5\%) were married. This high percentage was expected due to the age composition of the deceased population (more than $50.8 \%$ of the deceased were over 75 years old) since age is directly related to marriage. In this study, $63.5 \%$ of the dead were residents of the city; in this regard, factors such as access to transportation facilities, economic situation, and social elements can play a role. In urban society, due to easier access to services and favorable socio-economic status, most deaths occur in hospitals. However, one should not forget the cultural factors, social customs, and beliefs in how the person is cared for at the time of death. Based on the findings of this study, $78.1 \%$ of the deceased were hospitalized in the intensive care unit (ICU). According to studies, the mortality rate in intensive care units is high (about 50\%). However, this ward should not be considered a place for the patient to die; thus, it is important to select the patient to be admitted to the intensive care unit. Also, due to the high cost of hospitalization in this ward, patients who really need intensive care with the hope for recovery should be hospitalized there $[12,13]$. On the other hand, patients admitted to the intensive care unit, due to different connections such as ventilation ducts and feeding tubes, are at risk of +ventilation pneumonia and various infections, especially urinary and respiratory tract [14]. Therefore, in the intensive care unit, the patients' condition is relatively worse than those admitted to other wards, and they typically have an underlying disease other than the cause of death, slowing down the treatment process. However, the equipment and facilities available in this ward reduce patient mortality; of course, they need to be checked periodically.

In this study, the most common cause of death was internal diseases (38.8\%) followed by neurological diseases (14.2\%), which was in line with that of Fayazi et al. [15] in Shahid Mohammadi Hospital in Bandar Abbas but inconsistent with that of Ali Mahmoudi et al. [1] in Khorramabad Martyrs' Hospital, who reported the most common cause of death as trauma and accidents (28.5\%).

The limitations of this research were the inconsistency of the hours recorded in the files, as well as the lack of access to the details of deaths in some departments, sufficient details of cardiac resuscitation, and accurate ICD coding in a number of death cases, leading to incomprehensive conclusions in the study. Therefore, future studies are suggested considering mortality hours and cardiac resuscitation details. More comprehensive studies by taking variables and statistical population into account are needed to generalize the results to the whole community.

\section{Conclusion}

This study examines the most important factors affecting mortality at the hospital level and shows that internal diseases are one of the most important causes of mortality, needing health policymakers' attention to control and prevent the diseases. Furthermore, attention to the length of hospitalization of patients (by assessing the relationship between complications due to prolonged hospital stay and mortality) can have a significant impact on controlling mortality. Also, considering the factors that increase the number of days hospitalized, especially in the elderly and women, can help identify strategies to reduce hospital mortality.

\section{Acknowledgement}

This article results from a research project approved by Rafsanjan University of Medical Sciences with the code of ethics IR.RUMS.REC.1398.165. The authors are grateful to the Social Health Research Center of Rafsanjan University of Medical Sciences for their financial and spiritual support.

Conflict of interest: None declared.

\section{References}

1. Mahmoudi GA, Astaraki P, Anbari K, Khayat Pisheh S. Epidemiolgical Survey of Mortality Rate in Patients Admitted to Shohada Hospital of Khorramabad in 2011. Scientific Journal of Forensic Medicine 2014; 20(1):393-400. 
2. Bates DW, Singh H. Two Decades Since to Err is Human: An Assessment of Progress and Emerging Priorities in Patient Safety. Health Aff (Millwood) 2018; 37(11):1736-43.

3. Wang $\mathrm{H}$, Dwyer-Lindgren $\mathrm{L}$, Lofgren $K T$, Rajaratnam JK, Marcus JR, Levin-Rector A, et al. Age-specific and sex-specific mortality in 187 countries, 1970-2010: a systematic analysis for the Global Burden of Disease Study 2010. Lancet 2012; 380(9859):2071-94.

4. Faghihi $F$, Jafari $N$, Akbari Sari A, Nedjat S, Hosainzadeh M. Trend of Mortality Rate and Causes of Death in Qazvin Province, 20042008. Scientific Journal of Forensic Medicine 2015; 21(1):35-42.

5. Murray CJ, Lopes AD. Mortality by cause for eight regions of the World: Global Burden of Disease Study. Lancet 1997; 349(9061):126976.

6. Mackentoach JP, Kunst AE, Lautenbach $H$, Bijlsma F, Oei YB. Competing causes of death: an analysis using multiple-cause-of-death data from The Netherlands. Am J Epidemiol 1995; 141(5):466-75.

7. Ahlbom A. Eylenbosch WJ, Noah NG, eds. Surveillance in Health and Disease. Scand $\mathrm{J}$ Soc Med 1990; 18(3):237.

8. Gudarzi F. Forensic medicine. 2nd ed. Tehran: Einstein; 1996.

9. Lu TH, Lee MC, Chou MC. Accuracy of cause- of-death coding in Taiwan: types of miscoding and effects on mortality statistics. Int $\mathrm{J}$ Epidemiol 2000; 29(2):336-43.

10. Sepandi M, Jalali A, Alidadi A, Pour Ebrahimi M, Zarbizadeh A, Mahmoudi N. Epidemiologic Study on Causes of Mortality among Hospitalized Patients. Health Research Journal 2016; 1(4):199-206.

11. Garkaz O, Taghdir M, Sepandi M. The Analytical study of the Main Causes of Mortality of Patients in the ICU Section of the Selected Military Hospital between 2012-2017. Health Research Journal 2019; 4(3):129-36.

12. DeKeyser Ganz F, Fink NF, Raanan O, Asher $M$, Bruttin $M$, Nun MB, et al. ICU nurses' oral-care practices and the current best evidence. J Nurs Scholarsh 2009; 41(2):132-8.

13. Shirey MR. Authentic leadership, organizational culture, and healthy work environments. Crit Care Nurs Q 2009; 32(3):189-98.

14. Koushali AN, Hajiamini Z, Ebadi A. Comparison of nursing students' and clinical nurses' attitude toward the nursing profession. Iran $\mathrm{J}$ Nurs Midwifery Res 2012; 17(5):375-80.

15. Fayazi N, Mahouri K, Zare S, Gharibpour A, Ravagh M. Mortality in Shahid Mohammadi hospital of Bandar Abbas, first half of 2004. Hormozgan Medical Journal 2006; 10(3):e90047. 